〔Med. Entomol. Zool. Vol. 55 No. 3 p. 201-210 2004〕

\title{
A new species of Simulium (Nevermannia) (Diptera: Simuliidae) from Japan
}

\author{
Hiroko SATO ${ }^{1)}$, Hiroyuki TAKAOKA ${ }^{1)}$ and Masako FukUdA ${ }^{1), 2)}$ \\ 1) Department of Infectious Disease Control, Faculty of Medicine, Oita University, \\ Hasama, Oita, 879-5593 Japan \\ 2) Division of Epidemiology, Culture and Communication, Institute of Scientific Research, \\ Oita University, Hasama, Oita, 879-5593 Japan
}

(Received: 2 March 2004; Accepted: 14 May 2004)

\begin{abstract}
A new black-fly species, Simulium (Nevermannia) uemotoi sp. nov., is described based on female, male, pupal and mature larval specimens collected from Oita, Japan. This new species is assigned to the vernum species-group and is distinguished from other known related species by a combination of the following characters: katepisternum with several hairs on each side and 1st and 2nd segments of maxillary palp ocherous in both sexes of adults; frons with two long and one short trichomes on each side, gill with four slender thread-like filaments and simple wallpocket-shaped cocoon in the pupa; and small, M-shaped or rounded postgenal cleft and simple rectal organ in the larva. A new name $S$. $(N$.) ono $i$ is given for the species which was collected from Hokkaido and erroneously identified as Cnetha konoi by Ono.
\end{abstract}

Key words: black fly, new species, Simuliidae, Simulium, Nevermannia, vernum species-group

Thirteen species and one subspecies of the subgenus Simulium (Nevermannia) are known to exist in Japan, of which eight species and one subspecies are placed in the vernum species-group: viz. S. acmeria (Ono), S. boldstemta (Ono), S. bonninense (Shiraki), S. sp. (= "Cnetha konoi" by Ono), S. larvipilosum Okazawa, S. rebunense (Ono), S. subcostatum subcostatum (Takahasi), S. subcostatum koshikiense Takaoka and S. uchidai (Takahasi) (Crosskey and Howard, 1997). We collected a new species of this species-group from Oita, Kyushu Island, which is conspecific to Eusimulium sp. 2 reported by Orii et al. (1969), E. sp. 3 by Onishi et al. (1971), S. (E.) sp. by Takaoka et al. (1977), and S. (E.) sp.-H by Saito and Kanayama (1988).

This is described as a new species based on female, male, pupal and larval specimens collected from Oita, Japan. The morphological features and their terms used follow Takaoka (2003). Holotype and paratype specimens are deposited in the Natural History Museum in London, U.K.

\section{Simulium (Nevermannia) uemotoi sp. nov.}

Eusimulium sp. 2: Orii, Uemoto and Onishi (1969): 2 (parts of larva).

Eusimulium sp. 3: Onishi, Uemoto and Orii (1971): 77 (parts of male, pupa and larva).

Simulium (Eusimulium) sp.: Takaoka, Ochoa and Yamamoto (1977): 342.

Simulium (Eusimulium) sp.-H: Saito and Kanayama (1988): 381.

DESCRIPTION. Female. Body length 2.3 mm. Head. Narrower than thorax. Frons and clypeus medium to dark brown, slightly shiny at certain angles of light and thinly white pruinose, densely covered with yellowish fine hairs. Frontal ratio 1.8:1.0:2.6; frons-head ratio $1.0: 5.0$. Fronto-ocular area (Fig. 1) well developed, directed laterally and upwardly. 
Labrum 0.62 times as long as clypeus. Antenna (Fig. 2) composed of $2+9$ segments, light brown, except scape, pedicel and base of 1st flagellar segment yellow; 1st flagellar segment somewhat elongate, 1.5-1.6 times as long as 2nd one; 9 th flagellar segment also somewhat elongate, 1.4-1.6 times as long as 8th one. Maxillary palp composed of 5 segments, 1 st and 2nd segments ocherous, 3rd and 4th segments medium brown, 5th segment light brown; proportional lengths of $3 \mathrm{rd}$, 4th and 5th segments $1.0: 0.9-1.0: 2.3-2.4$; 3rd segment (Fig. 3) somewhat enlarged; sensory vesicle elongate, 0.6 times as long as 3rd segment, with mediumsized opening. Lacinia with 13 inner and 12 or 13 outer teeth. Mandible with 30-32 inner and 12 or 13 outer teeth. Cibarium (Fig. 4) simple. Thorax. Scutum dark brown except anterolateral calli ocherous, slightly shiny at certain angles of light, densely covered with yellow recumbent scale-like hairs as well as yellow long upright hairs on prescutellar area. Scutellum light brown, with yellow short and long hairs. Postnotum medium brown, bare, slightly shiny at certain angles of light. Pleural membrane bare. Katepisternum longer than wide, medium to dark brown, slightly shiny at certain angles of light, with 4 or 5 short fine hairs near upper margin on each side. Legs. Foreleg (Fig. 5): coxa and trochanter yellow; femur ocherous except basal $1 / 4$ or $1 / 3$ yellow and apical cap light brown; tibia yellow except apical 1/4 medium brown; tarsus dark brown, with moderate dorsal hair crest; basitarsus somewhat dilated, 6.3 times as long as its greatest width. Midleg (Fig. 6): coxa medium brown; trochanter yellow; femur ocherous to dark yellow except basal $2 / 5$ yellow and apical cap light brown; tibia yellow except apical $1 / 3$ medium brown; tarsus medium to dark brown. Hind leg (Fig. 7): coxa light brown; trochanter yellow; femur ocherous or dark yellow except basal $1 / 3$ yellow and apical cap medium brown; tibia yellow except apical cap medium brown; tarsus light to dark brown; basitarsus slender, parallel-sided, 5.9 times as long as wide, and 0.8 and 0.7 times as wide as the greatest width of tibia and femur, respectively; calcipala 1.1 times as long as wide, and 0.46 times as long as the greatest width of basitarsus; pedisulcus well developed. All tarsal claws (Fig. 8) with large basal tooth 0.52 times as long as claw. Wing. Length ca. $2.5 \mathrm{~mm}$. Costa with dark spinules as well as whitish-yellow hairs except longer hairs near base pale. Subcosta fully haired on ventral surface. Basal portion of radial vein fully haired; $\mathrm{R}_{1}$ with spinules as well as hairs on dorsal surface; $R_{2}$ with hairs on ventral surface. Hair tuft at base of radial vein dark brown. Basal cell absent. Abdomen. Basal scale yellowish or ocherous, with whit ish-yellow long hairs. Dorsal surface of segment 2 yellowish or ocherous, with tergite slightly shiny at certain angles of light; dorsal surfaces of segments 3-6 not shiny, medium brown except submedial portion on each side of tergite widely ocherous; those of segments 7 and 8 each with tergite large, light brown, shiny at certain angle of light; dorsal surfaces of segments 3-9 covered with dark hairs interspersed with yellowish hairs. Ventral surface of 2nd segment yellowish or ocherous; those of segments 3-7 light to medium brown; segment 7 with large sternal plate medially. Genitalia. Sternite 8 (Fig. 9) bare medially, with 8 or 9 stout hairs laterally on each side. Ovipositor valve (Fig. 9) nearly triangular, with round posteromedial corner, thin, membraneous (except narrow posteromedial portions along inner and posterior margins bare), densely covered with microsetae interspersed with 8 or 9 short hairs and 1 or 2 long hairs; inner margins slightly sinuous, not sclerotized. Genital fork (Fig. 10) of usual inverted-Y shape; arm rather wide and strongly folded apically, with wide projection directed posteromedially. Paraproct (Figs. 11 and 12) slightly produced ventrally, with 24 or 25 long hairs on lateral and ventral surfaces, and with 6 or 7 sensilla on inside surface. Cercus (Fig. 12) about half as long as wide, rounded posteriorly. Spermatheca (Fig. 13) ovoid, well sclerotized (except small area near its juncture to duct unsclerotized) and with distinct reticulate surface pattern; internal setae appear to be absent; both accessory ducts slender, subequal in diameter to major one.

Male. Body length 2.5-3.2 mm. Head. Slightly wider than thorax; holoptic; upper eye consisting of 16 or 17 vertical columns and 15 horizontal rows of large facets. Face brownish black, white pruinose, with yellow hairs. Clypeus dark brown, white pruinose, with yellow hairs. Antenna (Fig. 14) composed of $2+9$ segments, medium brown except scape, pedicel and base of 1st flagellar segment yellow; 1st flagellar segment somewhat elongate, 1.8-2.1 times as long as 2nd one; Maxillary palp with 5 

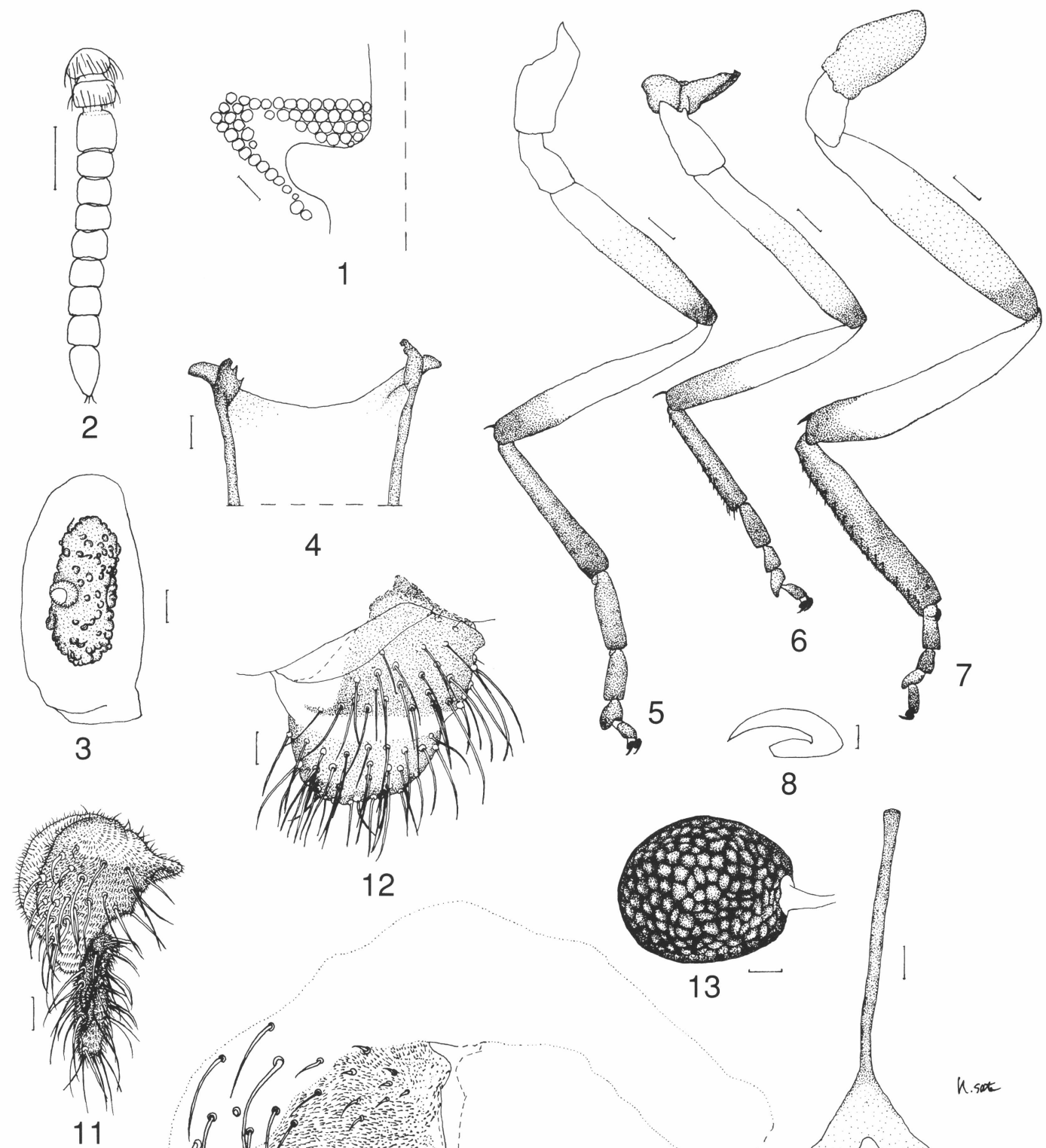

12
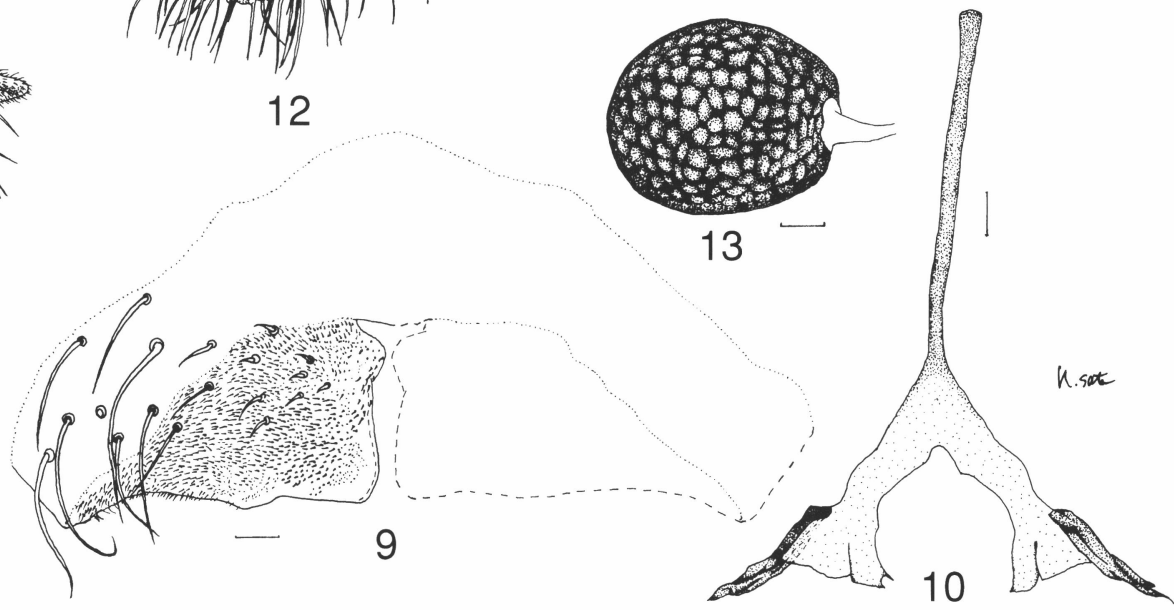

Figs. 1-13. Morphological characters of female of Simulium (Nevermannia) uemotoi sp. nov. 1, frontoocular area; 2, antenna; 3, 3rd segment of maxillary palp; 4, cibarium; 5, foreleg; 6, midleg; 7, hind leg; 8, claw; 9, genitalia in situ (ventral view); 10, genital fork; 11 and 12, paraprocts and cerci (11, ventral view; 12, lateral view); 13, spermatheca. Scales. $0.01 \mathrm{~mm}$ for Fig. 8; $0.02 \mathrm{~mm}$ for Figs. 3, 4 and 9-13; $0.04 \mathrm{~mm}$ for Fig. 1; $0.1 \mathrm{~mm}$ for Figs. 2 and 5-7.

segments, light to medium brown, except 1st and 2nd segments ocherous, proportional lengths of $3 \mathrm{rd}, 4$ th and 5 th segments $1.0: 1.1-$ $1.2: 2.2-2.8$; sensory vesicle (Fig. 15) small, 0.1-
0.2 times as long as 3rd segment, with mediumsized opening. Thorax. Scutum blackish brown (except anterolateral calli light brown and lateral and posterior margins brownish), 


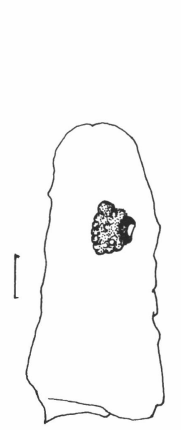

15

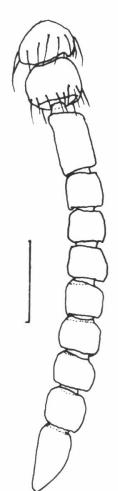

14
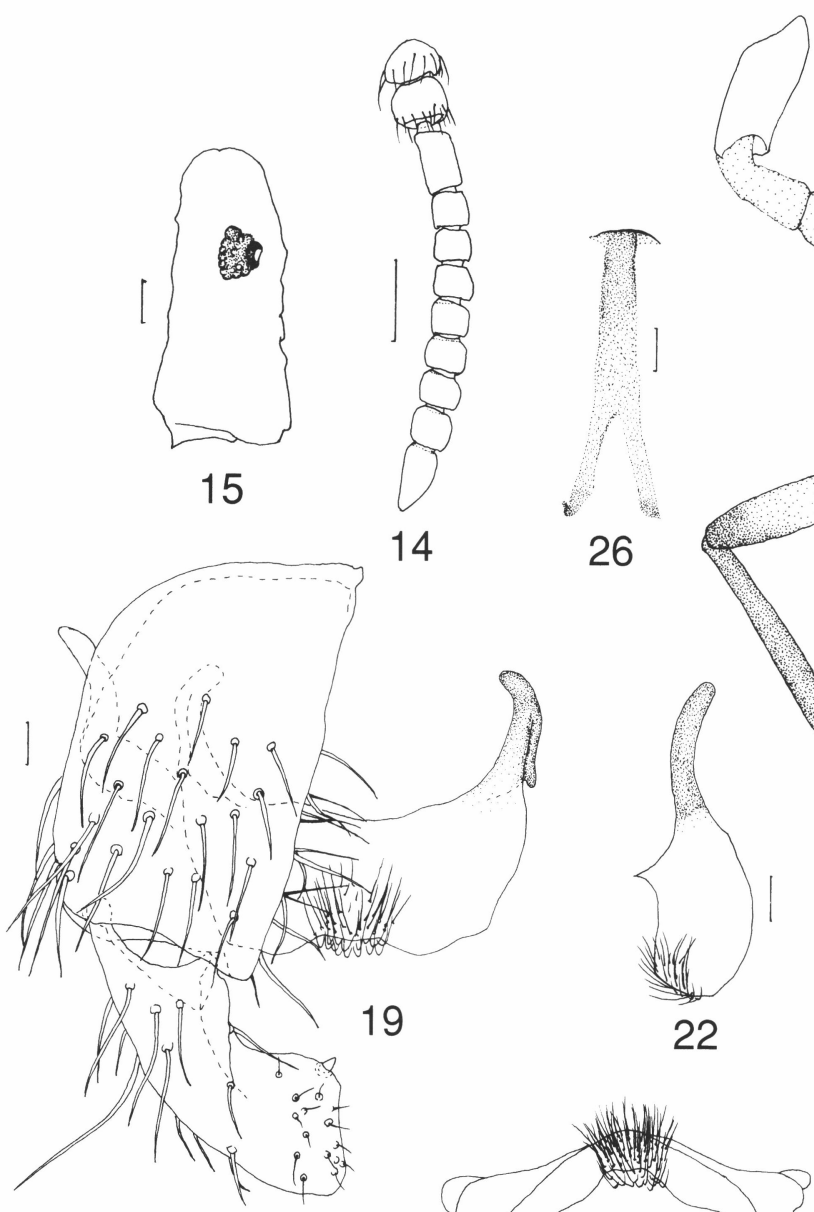

26
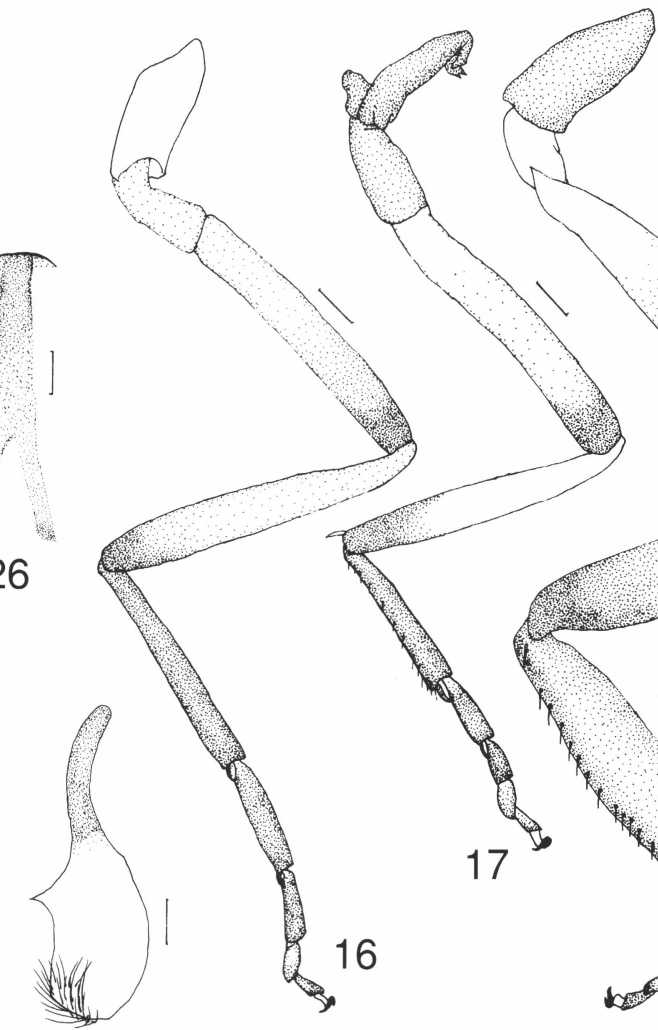

19
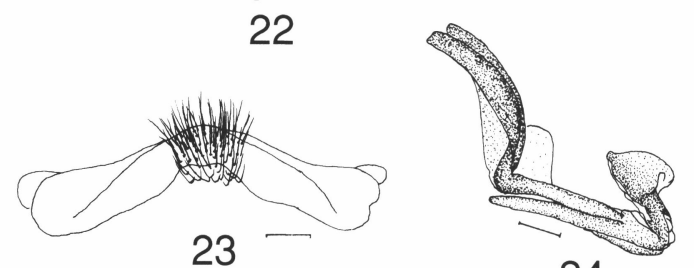

24
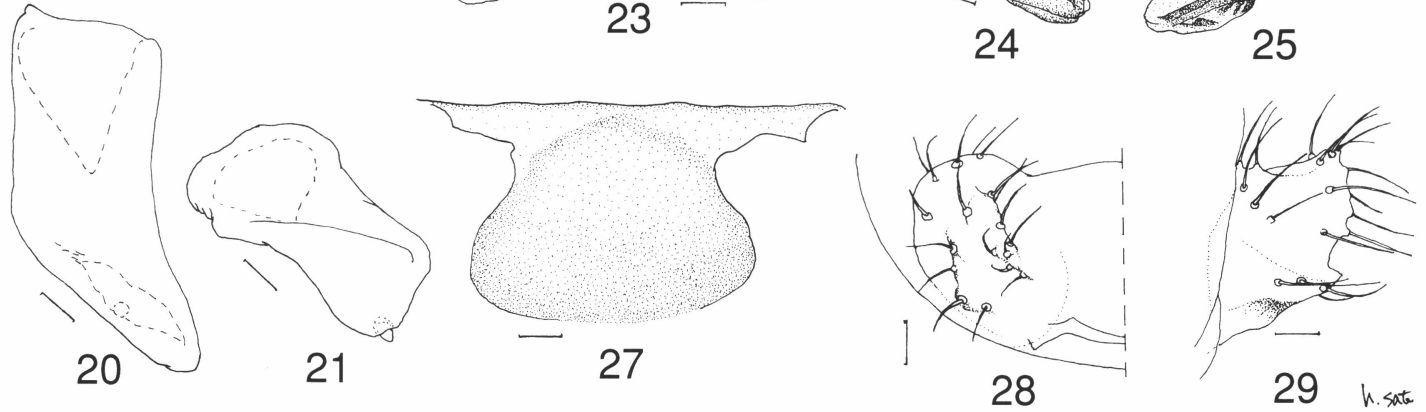

Figs. 14-29. Morphological characters of male of Simulium (Nevermannia) uemotoi sp. nov. 14, antenna; 15, 3rd segment of maxillary palp; 16, foreleg; 17, midleg; 18, hind leg; 19, genitalia in situ (ventral view); 20 and 21, styles (20, lateral view; 21, end view); 22 and 23, ventral plates (22, lateral view; 23, end view); 24 and 25, left parameres (24, dorsal view; 25, end view); 26, median sclerite; 27, dorsal plate; 28 and 29, 10th abdominal segments and cerci (28, end view; 29, lateral view). Scales. $0.02 \mathrm{~mm}$ for Figs. 15 and 19-29; $0.1 \mathrm{~mm}$ for Figs. 14 and 16-18.

not shiny (except narrow areas along lateral margins and prescutellar area shiny at certain angles of light) and densely covered with whitish-yellow recumbent hairs. Scutellum medium brown, with yellow long and short hairs. Postnotum medium brown, bare, shiny 
at certain angle of light. Pleural membrane bare. Katepisternum as in female. Legs. Foreleg (Fig. 16): coxa yellow; trochanter dark yellow or ocherous; femur dark yellow or ocherous with apical cap light to medium brown; tibia dark yellow or ocherous with apical 2/5 medium brown; tarsus dark brown to brownish black. Midleg (Fig. 17): coxa medium to dark brown; trochanter dark yellow to light brown; femur dark yellow or ocherous with base somewhat paler and apical cap medium brown; tibia yellow with apical $2 / 5$ dark brown; tarsus dark brown to brownish black. Hind leg (Fig. 18): coxa medium brown; trochanter yellow; femur dark yellow to light brown with basal $1 / 4$ yellow and apical cap dark brown; tibia yellow with apical $1 / 2$ dark brown, with faint dark lateral spot subbasally; tarsus medium to dark brown except basal 1/3 of 2nd tarsal segment dark yellow; basitarsus 4.4 times as long as wide, and equal in greatest width to hind tibia and femur; calcipala 1.1 times as long as wide, and 0.23 times as wide as the greatest width of basitarsus; pedisulcus well developed. Wing. Length $2.3-2.5 \mathrm{~mm}$. Other characters as in female except subcosta bare. Abdomen. Basal scale medium brown to brownish black with fringe of whitish-yellow long hairs. Dorsal surface of abdomen dark brown to brownish black (except basal portion of 2nd segment yellow), not shiny (tergite of 2nd segment shiny at certain angles of light), covered with dark hairs. Genitalia. Coxite (Fig. 19) in ventral view 1.5-1.8 times as long as wide. Style (Figs. 19-21) boot-shaped, about 0.9 times as long as coxite, twisted inwards, with apical spine. Ventral plate (Figs. 19, 22 and 23) in ventral view lamellate, transverse, much shorter than wide, setose medially, with posteromedial depression; arms well sclerotized, divergent, then somewhat convergent apically. Paramere (Figs. 24 and 25) with 1 large hook. Aedeagal membrane moderately covered with microsetae. Median sclerite (Fig. 26) forked apically. Dorsal plate (Fig. 27) well formed, thick; abdominal segment 10 (Figs. 28 and 29) with 8-10 short setae (of which 1 seta or 2 are located ventrally, while the others laterally) on each side. Cerci (Figs. 28 and 29) rounded, each encircled with 9-11 setae.

Pupa. Body length $2.3-3.2 \mathrm{~mm}$. Head. Integument (Fig. 30) medium yellowish-brown, moderately covered with round tubercles; antennal sheath normal, with no spinous projec- tions, and bare; face with 1 pair of simple long trichomes with coiled apex; frons with 3 pairs of simple trichomes ( 2 long with coiled apex and 1 short with uncoiled apex). Thorax. Integument medium yellowish-brown moderately or densely covered with round tubercles, with 3 pairs of simple long trichomes with coiled or uncoiled apex dorsally, with 2 pairs of simple trichomes ( 1 long and the other is medium-long with coiled or uncoiled apex) anterolaterally, with 1 pair of simple medium-long trichomes with uncoiled apex posterolaterally, and with 3 pairs of simple trichomes with uncoiled apex (their lengths are short or medium, differing from one another) ventrolaterally. Gill (Figs. 31 and 32) composed of 4 slender filaments, arranged in pairs (1 dorsal and the other ventral); each pair with short stalk arising from very short common basal stalk; stalk of dorsal pair directed upward while that of ventral pair directed somewhat outward; all filaments directed forward, almost the same in length $(3.5-5.1 \mathrm{~mm})$ and thickness (though lower filament of ventral pair somewhat shorter than the others in some pupae), tapered gradually toward apical tip, with distinct annular ridges and furrows and densely covered with minute tubercles on their surface. Abdomen. Dorsally, segments 1 and 2 light yellowish-brown and tuberculate; segment 1 with 1 simple long seta on each side; segment 2 with 1 simple medium-long seta and 5 somewhat spinous setae (4 in 1 pupa) submedially on each side; segment 3 light yellowish-brown on anterior $1 / 2$, pale on posterior $1 / 2$; segment 4 almost pale; segments 3 and 4 sparsely tuberculate medially, each with 4 hooks and 1 short spinous seta submedially on each side; segments 5-8 almost pale, each with distinct spine-combs in transverse row, together with comb-like groups of minute spines and 2 short spinous setae on each side; segment 9 with comb-like groups of minute spines, of which some developed to varying extents, appearing to be spine-combs (though much smaller than those on segments 5-8); segment 9 also with a pair of distinct simple cone-like terminal hooks (Fig. 33). Ventrally, segment 3 with a few simple slender minute setae on each side; segment 4 with 1 simple or bifid hooklet and 3 simple minute setae on each side; segment 5 with a pair of bifid hooks close together submedially and a few simple short slender setae on each side; segments 6 and 7 each with a pair 

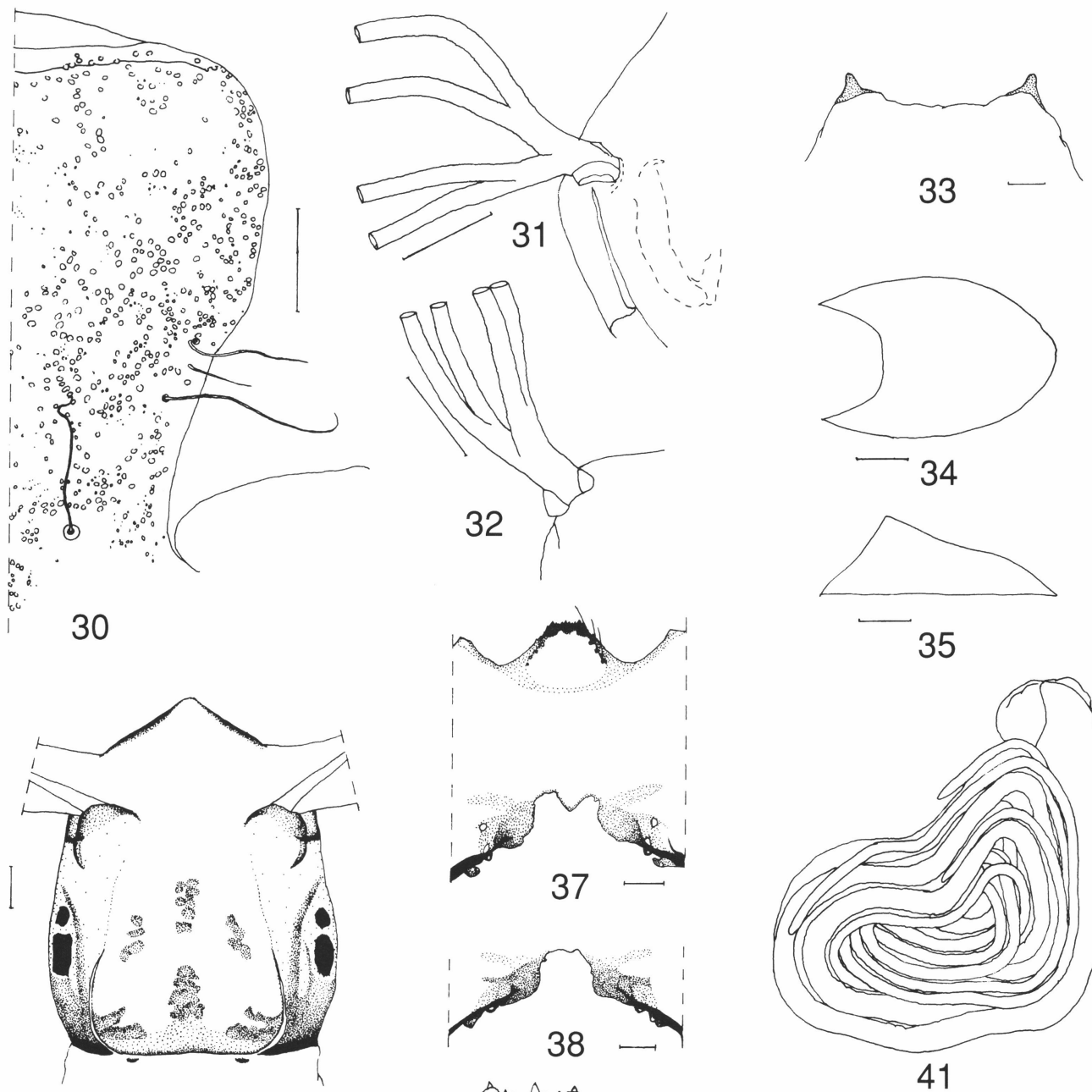

35

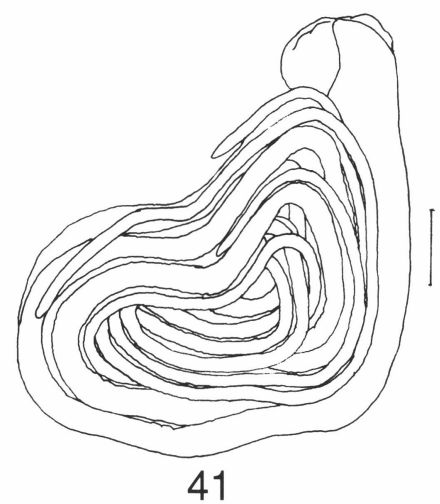

36
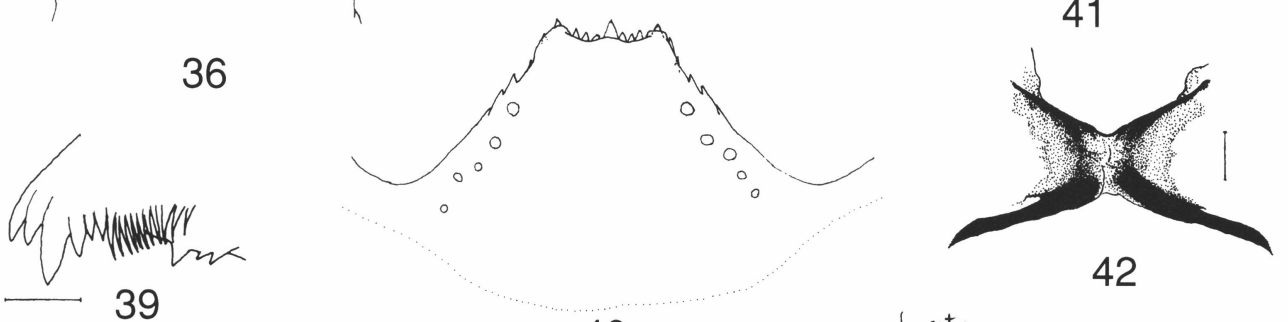

42

40

h. sat

Figs. 30-42. Morphological characters of pupa and mature larva of Simulium (Nevermannia) uemotoi sp. nov. 30-35, pupa and 36-42, larva. 30, integument of frons (left half); 31 and 32, basal portions of gill filaments (31, lateral view; 32, dorsal view); 33, terminal hooks (end view); 34 and 35, cocoons (34, dorsal view; 35, lateral view); 36, head capsule (dorsal view); 37, head capsule showing M-shaped postgenal cleft (ventral view); 38, round postgenal cleft; 39, apical portion of mandible; 40, hypostomium; 41, pharate pupal gill; 42, anal sclerite. Scales. $0.02 \mathrm{~mm}$ for Figs. 33 and 36-39; $0.04 \mathrm{~mm}$ for Figs. 40-42; $0.05 \mathrm{~mm}$ for Figs. 31 and 32; $0.1 \mathrm{~mm}$ for Fig. 30; $1.0 \mathrm{~mm}$ for Figs. 34 and 35.

of bifid inner and simple outer hooks somewhat separated from each other and a few simple short slender setae on each side. Each side of segment 9 without grapnel-like hook- lets. Cocoon (Figs. 34 and 35). Wall-pocketshaped, light ocherous, tightly woven without open spaces in webs, extending ventrolaterally; anterodorsal margin thickly woven; 4.0-5.0 
mm long by $2.7-3.3 \mathrm{~mm}$ wide.

Mature larva. Body length $6.0-6.8 \mathrm{~mm}$. Body color whitish yellow, somewhat greyish or light yellowish in most larvae; in 1 larva, abdominal segments $3-6$ each with a pair of small light-brown submedial spots dorsally. Abdomen narrower than thorax on segments 1-4 though gradually broadened posteriorly, abruptly swollen from anterior to posterior margins of segment 5 , broadest on segment 6 and gradually narrowed from segment 7 to segment 9. Cephalic apotome (Fig. 36) whitish yellow, somewhat darkened near posterior margin; head spots medium to dark brown, well defined. Lateral surface of head capsule yellow except eye-spot region white; eyebrow medium to dark brown, widely darkened posterior to eye-spot region; 1 small spot below eyespot region usually light to medium brown. Ventral surface of head capsule (Figs. 37 and 38) yellow with 1 elongate spot light to medium brown and 1 small spot fused to margin on each side of postgenal cleft; posterior margin heavily sclerotized as usual. Antenna much longer than stem of labral fan; proportional lengths of 1 st, 2 nd and 3rd segments 1.0 : 1.2-1.4: $0.8-1.0$. Labral fan with 36 or 37 main rays. Mandible (Fig. 39) with comb-teeth of different lengths (1st longest and 2nd shortest); mandibular serrations composed of 2 teeth (1 large and 1 small); large tooth at an obtuse angle with the mandible on apical side; 1 supernumerary serration present (rarely absent). Hypostomium (Fig. 40) with 9 apical teeth in row; medial tooth subequal in length to each corner tooth, much longer than 3 intermediate teeth on each side; lateral margin moderately serrated apically; 4 or 5 hypostomal bristles per side, lying nearly parallel to lateral margin. Postgenal cleft small, M-shaped (Fig. 37) in 6 larvae or rounded anteriorly (Fig. 38) in 1 larva, $0.6-0.7$ times as long as postgenal bridge. Cervical sclerites (Fig. 36) composed of 2 small rod-like pieces, not fused to occiput, widely separated medially from each other. Pharate pupal gill as in Fig. 41. Thoracic cuticle almost bare. Abdominal cuticle almost bare except segments 5-8 sparsely covered with simple slender setae on dorsal surface, and each side of anal sclerite of last segment (down to middle of ventral papillae) moderately covered with simple setae. Rectal scales distinctly discernible. Rectal organ simple, each of 3 lobes without secondary lobules. Anal sclerite (Fig. 42) of usual X-form, with anterior arms 0.8-0.9 times as long as posterior ones, broadly sclerotized at base; accessory sclerite and sensillum absent; last abdominal segment expanded ventrolaterally forming double bulges on each side, visible as a large conical ventral papilla when viewed from side. Posterior circlet with 82-84 rows of up to 12 or 13 hooklets per row.

TYPE SPECIMENS. Holotype: Female (preserved in 80\% ethanol), reared from pupa collected from a small stream flowing along the road from Nagayu and Taketa at the village of Yamaji (E131 $21^{\prime} 77^{\prime \prime} / \mathrm{N} 33^{\circ} 18^{\prime}$ ), Kuju, Oita, Japan, 1. VIII. 2003, by H. Takaoka, Y. Otsuka and M. Fukuda. Paratypes: 5 males, 6 pupae and 7 mature larvae (preserved in $80 \%$ ethanol), same data as holotype.

BIOLOGICAL NOTES. The larvae and pupae were attached to trailing grass leaves in a stream with moderate flow (width 1.5-2.0 m, stream bed rocky with sands and stones, water temperature $18.0^{\circ} \mathrm{C}$, exposed to sun, altitude ca. $550 \mathrm{~m}$ ). Associated species were $S$. aokii, $S$. arakawae, S. bidentatum, S. japonicum, S. nikkoense and S. uchidai.

DISTRIBUTION. Japan (Hokkaido, Honshu, Kyushu and Shikoku)

ETYMOLOGY. The species name uemoto $i$ is in honor of Dr. K. Uemoto, taxonomist of Simuliidae, who discovered this new species in 1969. The Japanese name of this new species is Hakusantsunomayubuyu, as proposed by Orii et al. (1969).

REMARKS. Simulium uemotoi sp. nov. is assigned to the vernum species-group by the male ventral plate lamellate, without median keel, style elongate with a large, broad, inwardly-twisted apex, paramere with a single hook, and median sclerite inverted Y-shaped; pupal gill with four slender filaments per side; and larval mandible with supernumerary serrations. This species is distinctive in having the 


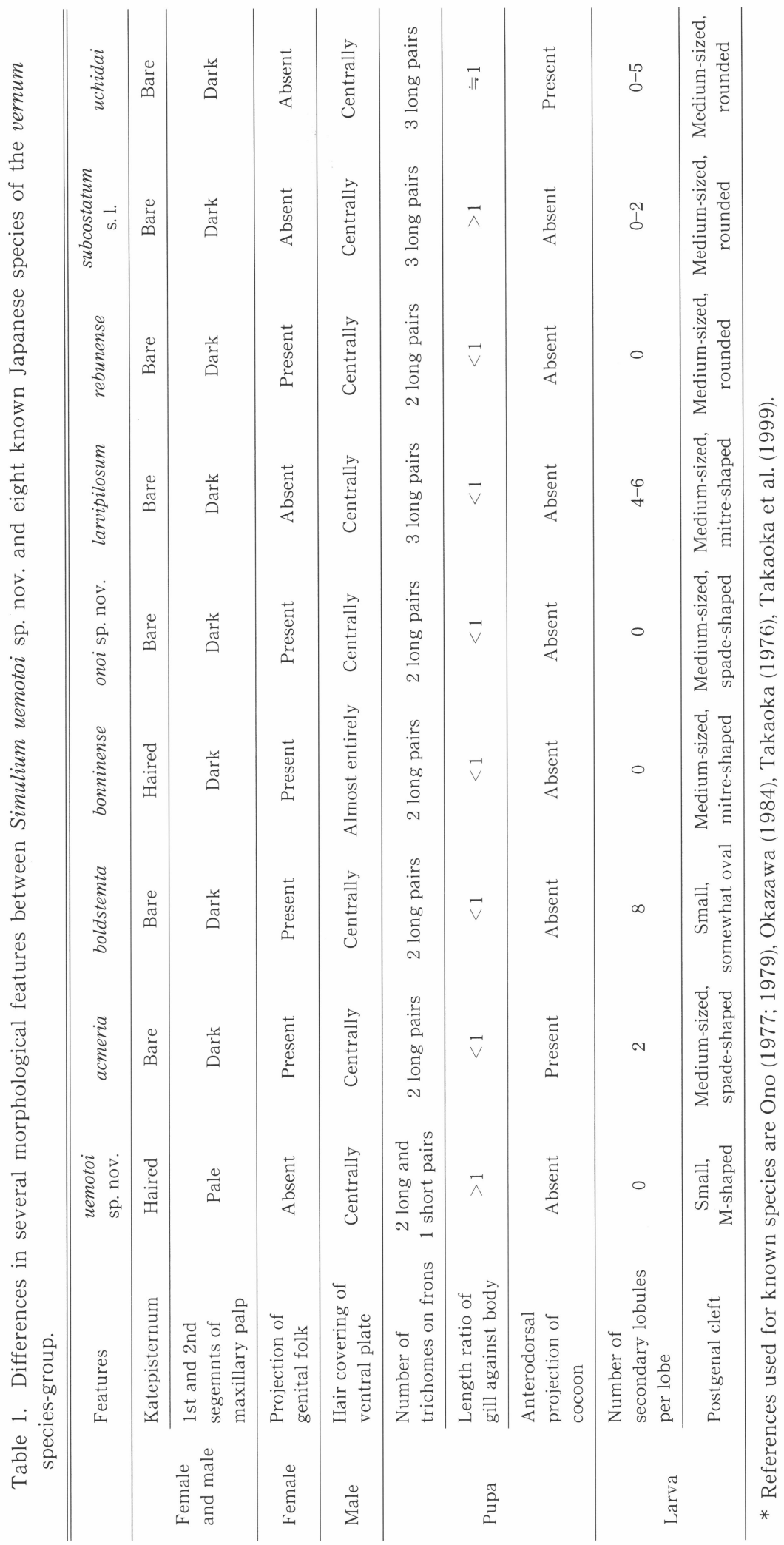


following two characters, which occur very rarely among species of the vernum species-group: katepisternum with several hairs on each side in both sexes of adults, and larval postgenal cleft small and Mshaped or rounded. In having hairs on the katepisternum, S. uemotoi appears to be somewhat related to S. bonninense (Shiraki) reported from the Ogasawara Islands (Takaoka et al., 1999). However, S. uemotoi differs from the latter species in many features including female genital fork without a projection directed anteriorly, male ventral plate with setae only centrally on the ventral surface. On the other hand S. karzhantavicum (Rubtsov) reported from Turkmenia (Rubtsov, 1956) is the only known species which has a small M-shaped postgenal cleft, like $S$. uemotoi. However, there are differences in the color of the legs and shape of the genital fork between the two species. In $S$. karzhantavicum the female and male legs are entirely black, and the genital fork has a distinct projection directed anteriorly on each arm.

S. uemotoi is easily distinguished from the eight known species of the vernum species-group in Japan as shown in Table 1 .

\section{APPENDIX}

During our study of the vernum speciesgroup so far reported from Japan, Dr. H. Ono (pers. commun.) informed that the species reported from Hokkaido as Cnetha konoi by himself in 1979 is not S. konoi (Takahasi, 1950) (unplaced to any speciesgroup within the subgenus Nevermannia), but represents a new species of the vernum species-group, as evidenced by the descriptions and illustrations (Ono, 1979). This species is here named S. ono $i$ Sato and Takaoka sp. nov. in honor of Dr. H. Ono, who discovered this new species. This species is distinguished from any other known species of this species-group by the unusually numerous teeth on the female mandible (i.e. 28 or 29 outer teeth and 40-46 inner teeth) and larval mandible with only one major tooth (lacking a small minor tooth as well as supernumerary serrations). S. onoi appears to be closely related to $S$. acmeria, $S$. boldstemta, $S$. bonninense and $S$. rebunense in that it has a projection directed anteriorly on each arm of the genital folk. However, this species is easily distinguished from S. acmeria by the simple cocoon, from S. boldstemta by the simple rectal organ, from $S$. bonninense by the bare katepisternum, and from $S$. rebunense by the shape of the larval postgenal cleft.

\section{ACKNOWLEDGEMENTS}

We are grateful to Dr. K. Uemoto, Kyoto, Japan, for his generousity in allowing us to describe this new species. Thanks are due to Dr. K. Saito, Kanagawa, Japan, who kindly provided valuable references and unpublished information on the geographical distribution of S. uemotoi. Our appreciation goes to Dr. Y. Otsuka for his help in collecting simuliid larvae and pupae in the field. Finally we thank Dr. H. Ono, Obihiro University, Hokkaido, Japan, for his valuable information.

\section{REFERENCES}

Crosskey, R. W. and Howard, T. M. 1997. A New Taxonomic and Geographical Inventry of World Blackflies (Diptera: Simuliidae), 144 pp. Nat. Hist. Mus., London.

Okazawa, T. 1984. A new species of Simulium (Eusimulium) (Diptera, Simuliidae) from Hokkaido, Japan. Kontyu, 52: 213-221.

Onishi, O., Uemoto, K. and Orii, T. 1971. On the new-recorded species of black fly (Eusimulium) from Japan. II. Proceedings of the 23rd Annual Meeting of Japanese Society of Sanitary Zoology: 77 (English abstract only).

Ono, H. 1978. Description of the two new species of the genus Cnetha from Japan (Diptera, Simuliidae). Res. Bull. Obihiro Univ., 10: 893-909.

Ono, H. 1979. A new species of the genus Cnetha from Hokkaido, Japan with redescription of Cnetha konoi (Takahasi, 1950) (Diptera, Simuliidae). Jpn. J. 
Sanit. Zool., 30: 253-254.

Orii, T., Uemoto, K. and Onishi, O. 1969. Key to larval stage of black flies (Simuliidae) of Japan. Sanitary Injurious Insects, 13: 1-13 (In Japanese).

Rubtsov, I. A. 1956. Blackflies (Simuliidae). Fauna of the USSR. 2nd ed. New Series No. 61, Diptera 6 (6): xxiii 1042 pp., Acad. Sci. USSR, Moscow and Leningrad (translated from Russian by Amerind Publ. Co. Pvt. Ltd., New Delhi, India, 1989).

Saito, K. and Kanayama, A. 1988. Studies on the ecology of blackflies (Diptera: Simuliidae) (15). Fauna of the blackflies in Osaka Prefecture in spring. Jpn. J. Sanit. Zool., 39: 379-382 (In Japanese with English summary).

Takaoka, H. 1976. Studies on black flies of the Nansei Islands, Japan (Simuliidae; Diptera) I. On six species of the subgenus Eusimulium Roubaud, with the descriptions of Simulium (E.) satsumense sp. nov. and Simulium (E.) subcostatum koshikiense ssp. nov. Jpn. J. Sanit. Zool., 27: 163-180.

Takaoka, H. 2003. The Black Flies (Diptera: Simuliidae) of Sulawesi, Maluku and Irian Jaya. xxii +581 pp., Kyushu University Press., Fukuoka.

Takaoka, H., Ochoa, J. O. and Yamamoto, S. 1977. Notes on the fauna and distribution of black-flies in Kyushu, Japan (Simuliidae; Diptera). Jpn. J. Sanit. Zool., 28: 341-347 (In Japanese with English summary).

Takaoka, H., Saito, K. and Suzuki, H. 1999. Simulium (Nevermannia) bonninense from the Ogasawara (Bonin) Islands, Japan (Diptera: Simuliidae): Taxonomic assignment to the vernum-group and descriptions of male, pupa and mature larva. Jpn. J. Trop. Med. Hyg., 27: 189-194. 